\title{
COMPORTAMENTO DA ALFACE TIPO AMERICANA SOB DIFERENTES TENSÕES DA ÁGUA NO SOLO, EM AMBIENTE PROTEGIDO ${ }^{1}$
}

\author{
SILVÂNIO R. DOS SANTOS ${ }^{2}$, GERALDO M. PEREIRA ${ }^{3}$
}

RESUMO: Visando a definir critérios para o manejo da irrigação para alface tipo americana, cv. Raider, esse trabalho foi desenvolvido para avaliar o efeito de diferentes tensões da água no solo sobre o comportamento produtivo da cultura, em ambiente protegido, na região de Lavras - MG. O experimento foi instalado em casa de vegetação com delineamento em blocos casualizados, tendo quatro repetições. Os tratamentos foram constituídos de seis tensões de água no solo como indicativas do momento de irrigar. As tensões preestabelecidas foram 15;30; 45; 60; 75 e $90 \mathrm{kPa}$, à profundidade de $0,15 \mathrm{~m}$. Os resultados permitiram concluir que, no emprego de tensões em torno de $15 \mathrm{kPa}$, há tendência em obter plantas mais altas, com maior peso de matéria fresca comercial e menor teor de matéria seca da parte comercial. Também foi possível observar melhor eficiência no uso da água $\left(469,22 \mathrm{~kg} \mathrm{ha}^{-1} \mathrm{~mm}^{-1}\right)$ sob tensão de $15 \mathrm{kPa}$.

PALAVRAS-CHAVE: irrigação por gotejamento, manejo da irrigação, estresse hídrico.

\section{BEHAVIOR OF CRISPHEAD LETTUCE UNDER DIFFERENT SOIL WATER TENSIONS, IN A PROTECTED ENVIRONMENT}

SUMMARY: Seeking to define a criteria for irrigation scheduling of lettuce cultivated in a protected environment in the region of Lavras - MG, Brazil, the purpose of this work was to evaluate the effects of different soil water tensions in the crisphead lettuce, Raider $c v$., on productive behavior. The experiment was carried out in a greenhouse following the completely randomized blocks design with four replications. The treatments consisted of six water tensions as indicatives of the irrigation schedule criteria. Preset tensions were 15; 30; 45; 60; 75 and $90 \mathrm{kPa}$. Results allowed concluding that under tensions around $15 \mathrm{kPa}$ at a $0.15 \mathrm{~m}$ depth, there is a tendency in obtaining taller plants, featuring more fresh matter weight of marketable head, and lower dry matter contents in the marketable part. It was also possible to obtain a better efficiency water use $\left(469.22 \mathrm{~kg} \mathrm{ha}^{-1} \mathrm{~mm}^{-1}\right)$ under tensions around $15 \mathrm{kPa}$.

KEYWORDS: drip irrigation, irrigation scheduling, water stress.

\section{INTRODUÇÃO}

A alface é a principal folhosa produzida no Brasil, sendo os Estados de São Paulo e Minas Gerais os maiores produtores (IBGE, 1996). Em Minas Gerais, a região Sul ocupa posição de destaque no cultivo dessa hortaliça, devido ao clima favorável e ao fato de estar próxima a dois grandes centros consumidores, Belo Horizonte e São Paulo. Um grupo de alface que tem sido cultivado é o da americana, principalmente visando a atender a algumas redes de lanchonetes ("fast food"). A sua grande aceitação pelas redes de "fast food" deve-se, principalmente, pela capacidade de manter-se crocante quando em contato com altas temperaturas no interior dos sanduíches e também por

\footnotetext{
${ }^{1}$ Extraído da dissertação de mestrado do primeiro autor apresentada à Universidade Federal de Lavras. Trabalho financiado pelo CNPq.

${ }^{2}$ Eng $^{-}$Agrônomo, Mestre em Irrigação e Drenagem na Universidade Federal de Lavras (UFLA), Rua São Francisco, 14, PitaranaMontalvânia - MG, Fone: (0XX38) 3612.2029, e-mail: silvaniors@yahoo.com.br

${ }^{3}$ Eng $^{\mathrm{o}}$ Agrícola, Prof. Adjunto, Departamento de Engenharia, UFLA, Lavras - MG.

Recebido pelo Conselho Editorial em:19-12-2002

Aprovado pelo Conselho Editorial em: 23-6-2004
} 
conservar-se por um período de tempo maior após a colheita, isto é, apresentar maior capacidade de armazenamento (YURI et al., 2002).

O cultivo em ambiente protegido é uma ferramenta muito útil para a aquisição de alta produção e de produtos de excelente qualidade, por manter um clima mais propício ao desenvolvimento da cultura ao longo do ano (SEGOVIA et al., 1997). Além disso, o cultivo protegido pode amenizar problemas com pragas e doenças e reduzir o risco de perdas por ocasião de geadas ou chuvas. Ao se tratar de cultivo protegido, é imprescindível o emprego da irrigação, uma vez que essa é a única forma de repor a água consumida pela cultura. O manejo adequado da irrigação é importante não apenas por suprir essas necessidades hídricas das plantas, mas também por minimizar problemas com doenças e lixiviação de nutrientes, bem como gastos desnecessários com água e energia.

O ideal é que o manejo da irrigação seja feito levando-se em consideração fatores do solo, do clima e da planta. Mesmo assim, o emprego somente de sensores de solo, tanto para indicar o momento quanto para a quantidade de água a aplicar, mostra-se como uma alternativa viável, sendo de baixo custo e de relativa praticidade (FIGUÊREDO, 1998).

ANDRADE JÚNIOR (1994), desenvolvendo trabalho com uma cultivar de alface do tipo americana (Mesa 659) sob cultivo protegido, na região de Botucatu - SP, obteve máxima produção e matéria fresca por planta, com a aplicação de uma lâmina de água total de 142,3 mm. Nessa lâmina, a tensão da água no solo variou de $20,5 \mathrm{kPa}$ a $38,2 \mathrm{kPa}$ ao longo do ciclo da cultura, tensão essa monitorada de forma indireta por meio da umidade gravimétrica e da curva característica da água no solo.

SILVA \& MAROUELLI (1998) afirmam que as hortaliças cultivadas em solo, sob ambiente protegido e manejadas por gotejamento, de modo geral, apresentam melhor desempenho quando submetidas a tensões da água no solo mais próximas à capacidade de campo, isto é, entre $10,0 \mathrm{kPa} e$ $30,0 \mathrm{kPa}$, com o sensor instalado a $0,15 \mathrm{~m}$ de profundidade.

Apesar da importância dos cultivos em ambientes protegidos para a olericultura brasileira, ainda são insuficientes os resultados de pesquisa que subsidiem o aproveitamento do potencial dessa tecnologia nas diferentes regiões climáticas do País, notadamente aqueles necessários ao adequado manejo da irrigação. Nesse aspecto, há necessidade de serem quantificados, dentre outros, os efeitos dos fatores climáticos sobre a evapotranspiração da cultura e os níveis de tensão de água do solo capazes de promover uma produtividade ótima, sendo essas informações imprescindíveis para o correto controle da irrigação pelos operadores e técnicos de projetos de irrigação.

Nesse sentido, teve-se o objetivo de, no trabalho em questão, avaliar o efeito de diferentes tensões da água no solo sobre o comportamento produtivo da alface tipo americana, cv. Raider, cultivada em ambiente protegido, na região de Lavras - MG, visando a definir critérios para o manejo da irrigação.

\section{MATERIAL E MÉTODOS}

$\mathrm{O}$ experimento foi desenvolvido em casa de vegetação situada na área experimental do Departamento de Engenharia da Universidade Federal de Lavras (UFLA), no período compreendido entre maio e julho de 2002. A UFLA situa-se em Lavras, sul de Minas Gerais e está numa altitude média de 910 m, $21^{\circ} 14^{\prime}$ latitude Sul e $45^{\circ} 00^{\prime}$ longitude Oeste. De acordo com a classificação de Köeppen, a região apresenta clima $\mathrm{Cwa}$, ou seja, clima temperado suave, chuvoso, com inverno seco, temperatura média do mês mais frio inferior a $18^{\circ} \mathrm{C}$ e superior a $3{ }^{\circ} \mathrm{C}$, e o verão apresenta temperatura média do mês mais quente superior a $22{ }^{\circ} \mathrm{C}$.

A casa de vegetação foi construída com estrutura metálica do tipo teto em arco, apresentando $3,00 \mathrm{~m}$ de pé-direito, $4,50 \mathrm{~m}$ de altura no ponto mais alto, $30 \mathrm{~m}$ de comprimento e $7 \mathrm{~m}$ de largura 
$\left(210 \mathrm{~m}^{2}\right)$. Foi revestida, na parte superior, com filme plástico transparente aditivado anti-UV de $0,15 \mathrm{~mm}$ de espessura e, nas laterais, com tela antiafídeos.

O solo foi classificado como Latossolo Vermelho distroférrico (EMBRAPA, 1999). Amostras foram coletadas nas profundidades de 0 a $0,20 \mathrm{~m}$ e 0,20 a $0,40 \mathrm{~m}$ para a determinação da curva característica da água no solo e, a seguir, os valores encontrados foram ajustados (eqs. 1 e 2, respectivamente) ao modelo proposto por GENUCHTEN (1980). Foi considerada a tensão de 10,0 kPa como a correspondente à umidade na capacidade de campo.

$$
\begin{aligned}
& \theta=0,263+\frac{(0,721-0,263)}{\left[1+(0,686 \psi)^{1,528}\right]^{0,345}} \\
& \theta=0,260+\frac{(0,687-0,260)}{\left[1+(0,696 \psi)^{1,563}\right]^{0,360}}
\end{aligned}
$$

em que,

$\theta$ - umidade atual, $\mathrm{cm}^{3} \mathrm{~cm}^{-3}, \mathrm{e}$

$\Psi$ - tensão de água no solo, $\mathrm{kPa}$.

O delineamento utilizado foi o de blocos casualizados, com seis tratamentos e quatro repetições. Os tratamentos foram as tensões da água no solo correspondentes a $15 \mathrm{kPa}\left(\mathrm{T}_{1}\right), 30 \mathrm{kPa}\left(\mathrm{T}_{2}\right), 45 \mathrm{kPa}$ $\left(\mathrm{T}_{3}\right), 60 \mathrm{kPa}\left(\mathrm{T}_{4}\right), 75 \mathrm{kPa}\left(\mathrm{T}_{5}\right)$ e $90 \mathrm{kPa}\left(\mathrm{T}_{6}\right)$, determinadas pelos sensores instalados a $0,15 \mathrm{~m}$ de profundidade. Para isso, foi instalada uma bateria de seis tensiômetros de punção (três a $0,15 \mathrm{~m}$ de profundidade e três a $0,30 \mathrm{~m}$ ) para monitorar as tensões de $15 \mathrm{kPa}$ a $60 \mathrm{kPa}$ e outra bateria de sensores de matriz granular (Granular Matrix Sensor-GMS, Watermark ${ }^{\circledR}$ - 200 SS), também contendo seis sensores (três na profundidade de $0,15 \mathrm{~m}$ e três a $0,30 \mathrm{~m}$ de profundidade) e sorteada entre as quatro parcelas de cada tratamento, para monitorar as tensões de $75 \mathrm{kPa}$ a $90 \mathrm{kPa}$. Esses sensores ficaram distanciados $0,10 \mathrm{~m}$ entre si, $0,03 \mathrm{~m}$ da linha de plantas e $0,18 \mathrm{~m}$ da linha lateral de irrigação. As parcelas experimentais apresentaram as dimensões de $1,20 \mathrm{~m}$ de largura e 3,00 m de comprimento $\left(3,60 \mathrm{~m}^{2}\right)$. Foram utilizadas quatro linhas de plantas espaçadas de $0,30 \mathrm{~m}$ entre si e $0,30 \mathrm{~m}$ entre plantas, totalizando 40 plantas por parcela. Foram consideradas úteis as plantas das linhas centrais, descartadas duas plantas no início e duas no final (parcela útil com 1,08 $\mathrm{m}^{2}$ e 12 plantas).

Utilizou-se de sistema de irrigação por gotejamento, sendo as linhas laterais compostas por emissores com vazão de $1,99 \mathrm{~L} \mathrm{~h}^{-1}$ para uma faixa de pressão entre $50 \mathrm{kPa}$ a $350 \mathrm{kPa}$, empregando-se um gotejador para cada duas plantas. As linhas laterais foram conectadas diretamente às linhas principais de PVC que tinham, no início, válvulas de comando elétrico localizadas na saída do cabeçal de controle, sendo utilizada uma válvula para cada tratamento. Essas válvulas eram acionadas por um controlador programável, funcionando o tempo necessário para a reposição da lâmina acusada, indiretamente, pelos sensores de umidade. Buscava-se, em todas as irrigações, elevar a umidade do solo à capacidade de campo.

O cálculo do tempo de funcionamento do sistema de irrigação foi feito a partir da lâmina bruta média calculada, considerando a profundidade efetiva do sistema radicular igual a $0,30 \mathrm{~m}$ e estratificada em duas subcamadas $(0$ a $0,20 \mathrm{~m}$ e 0,20 a $0,30 \mathrm{~m})$. A subcamada de 0 a $0,20 \mathrm{~m}$ foi monitorada pelos sensores instalados a $0,15 \mathrm{~m}$ de profundidade e, na subcamada de 0,20 a $0,30 \mathrm{~m}$, os sensores foram instalados a $0,30 \mathrm{~m}$. A eficiência de aplicação de água do sistema foi adotada como 90\%. A partir da lâmina bruta total e dos valores de área ocupada por planta, número de emissores por planta e vazão média por emissor, chegava-se ao tempo de irrigação, de acordo com a eq.(3). 


$$
\mathrm{T}=\frac{\text { LBmédia } \mathrm{Sp}}{\text { e qa }}
$$

em que,

$\mathrm{T}$ - tempo de funcionamento do sistema de irrigação em cada tratamento, h;

LBmédia - lâmina bruta total, mm, considerando as duas subcamadas estratificadas $(0$ a $0,20 \mathrm{~m}$ e $0,20$ a $0,30 \mathrm{~m})$;

$\mathrm{Sp}$ - área ocupada por planta, $0,09 \mathrm{~m}^{2}$;

e - número de emissores por planta, 0,5 , e

qa - vazão média dos emissores, $\mathrm{Lh}^{-1}$.

A cultivar utilizada foi a Raider, do tipo americana. A adubação básica foi realizada nove dias antes do transplantio, tendo sido aplicadas quantidades com base na análise química do solo e recomendações da quinta aproximação (GOMES et al., 1999). Toda a adubação de cobertura foi realizada via fertirrigação e seguindo as recomendações da quinta aproximação (GOMES et al., 1999); porém, devido ao tipo de experimento (não se tinha uma mesma frequiência de irrigação), tornou-se possível a divisão das quantidades dos nutrientes em apenas quatro aplicações, de acordo com o momento de irrigar.

Do transplantio até início da diferenciação dos tratamentos (12 dias após o transplantio), foram aplicados $42 \mathrm{~mm}$ de água em cada tratamento, com auxílio de regador e 17,2;17,8;17,9; 19,6; 11,5 e $6,8 \mathrm{~mm}$, por meio do sistema de irrigação, para os tratamentos $\mathrm{T}_{1}, \mathrm{~T}_{2}, \mathrm{~T}_{3}, \mathrm{~T}_{4}, \mathrm{~T}_{5}$ e $\mathrm{T}_{6}$, respectivamente, visando a uniformizar o teor de água entre os tratamentos.

As variáveis analisadas foram altura de plantas, peso da matéria fresca da parte comercial (cabeça comercial), teor de matéria seca da parte comercial e eficiência no uso da água. Após análise de variância pelo teste $\mathrm{F}$ (nível mínimo de $5 \%$ de significância), essas variáveis foram submetidas à análise de regressão, ao mínimo de $5 \%$ de significância. Os coeficientes de determinação $\left(\mathrm{R}^{2}\right)$ de cada regressão foram submetidos ao teste t, ao mínimo de $5 \%$ de significância, tendo $n=6$.

\section{RESULTADOS E DISCUSSÃO}

O experimento foi desenvolvido durante o período propício do ano para a cultura na região, cujas temperaturas amenas propiciaram à planta expressar seu máximo potencial vegetativo. A temperatura média diária do ar observada no interior da casa de vegetação foi $18,5^{\circ} \mathrm{C}$, de acordo, pois, com a faixa de temperatura citada por YURI (2000) para a obtenção de máximo rendimento (entre $15^{\circ} \mathrm{C}$ e $20^{\circ} \mathrm{C}$ ).

As lâminas de água aplicadas após o início da diferenciação dos tratamentos (Irrig), bem como os totais aplicados (Total), computados desde o transplantio da cultura, podem ser verificadas na Tabela 1. Nota-se que a maior lâmina foi a do tratamento $T_{3}$. Essas lâminas foram aplicadas com maior frequiência em $T_{1}$, sendo essa freqüência diminuída à medida que se aumentaram as tensões da água no solo. Como consequiência, as lâminas médias aplicadas por irrigação foram menores nos tratamentos sob menores tensões.

A altura de plantas foi altamente influenciada pelas diferentes tensões de água aplicadas no solo e, para essa variável, o delineamento utilizado, a 5\% de probabilidade, não se mostrou eficiente. Portanto, não se justifica o controle local, ou seja, o delineamento, nesse caso, poderia ser o inteiramente casualizado (Tabela 2). Comportamento semelhante foi observado para a matéria fresca da parte comercial e o teor de matéria seca da parte comercial. As variações ocorridas para a altura de plantas são explicadas por uma regressão linear simples, com o nível de significância de $1 \%$, apesar também de haver outra regressão que explique essas variações, uma vez que os desvios foram significativos a $5 \%$ de probabilidade. A altura média obtida foi de $25,6 \mathrm{~cm}$. 
TABELA 1. Tensões da água no solo observadas no início das irrigações à profundidade de $0,15 \mathrm{~m}$, lâminas aplicadas após diferenciar os tratamentos (Irrig), total (Total) e média por irrigação (mpi), intervalo médio entre irrigações (TR) e número de irrigações (NI).

\begin{tabular}{ccrrrrr}
\hline \multirow{2}{*}{ Tratamentos } & \multirow{2}{*}{ Tensão $(\mathrm{kPa})$} & \multicolumn{3}{c}{ Lâmina $(\mathrm{mm})$} & \multirow{2}{*}{ TR (dia) } & \multirow{2}{*}{ NI } \\
\cline { 3 - 5 } & & Irrig & Total & mpi & & \\
\hline $\mathrm{T}_{1}$ & 15,0 & 93,4 & 152,7 & 7,8 & 3,3 & 12 \\
$\mathrm{~T}_{2}$ & 30,0 & 86,4 & 146,2 & 21,6 & 8,0 & 4 \\
$\mathrm{~T}_{3}$ & 45,0 & 107,3 & 167,2 & 26,8 & 8,3 & 4 \\
$\mathrm{~T}_{4}$ & 60,0 & 98,4 & 160,0 & 32,8 & 11,3 & 3 \\
$\mathrm{~T}_{5}$ & 75,0 & 75,5 & 128,9 & 37,7 & 19,5 & 2 \\
$\mathrm{~T}_{6}$ & 90,0 & 39,9 & 88,7 & 39,9 & 25,0 & 1 \\
\hline
\end{tabular}

TABELA 2. Resumo da análise de variância e de regressão para altura de plantas, matéria fresca da parte comercial (MFPC), teor de matéria seca da parte comercial (TMSPC) e eficiência no uso da água $(\mathrm{Ea})$ de plantas de alface.

\begin{tabular}{cccccc}
\hline Fonte de & \multirow{2}{*}{ GL } & \multicolumn{5}{c}{ QM } \\
\cline { 3 - 6 } Variação & & Altura $(\mathrm{cm})$ & MFPC $(\mathrm{g})$ & TMSPC $(\%)$ & Ea $\left(\mathrm{kg} \mathrm{ha}^{-1} \mathrm{~mm}^{-1}\right)$ \\
\hline Bloco & 3 & $0,58^{\mathrm{ns}}$ & $2.903,00^{\mathrm{ns}}$ & $0,06^{\mathrm{ns}}$ & $1.326,83^{\mathrm{ns}}$ \\
Tensão & 5 & $24,90^{* *}$ & $42.008,90^{* *}$ & $1,35^{* *}$ & $7.765,94^{\mathrm{ns}}$ \\
Resíduo & 15 & 1,16 & $6.197,63$ & 0,19 & $3.363,04$ \\
\hline Média & - & 25,6 & 532,2 & 3,2 & 422,3 \\
C.V. $(\%)$ & - & 4,21 & 14,8 & 13,5 & 13,7 \\
\hline Linear & 1 & $112,22^{* *}$ & $190.900,26^{* *}$ & $4,65^{* *}$ & $48,60^{\mathrm{ns}}$ \\
Quadrática & 1 & $2,65^{\mathrm{ns}}$ & $7.086,22^{\mathrm{ns}}$ & $0,48^{\mathrm{ns}}$ & $30.093,33^{* *}$ \\
Ln & 1 & $0,012^{\mathrm{ns}}$ & $8.342,94^{\mathrm{ns}}$ & $0,67^{\mathrm{ns}}$ & $5.254,68^{\mathrm{ns}}$ \\
Desvios & 2 & $4,80^{*}$ & $1.857,54^{\mathrm{ns}}$ & $0,46^{\mathrm{ns}}$ & $1.716,56^{\mathrm{ns}}$ \\
Resíduo & 15 & 1,16 & $6.197,63$ & 0,19 & $3.363,04$ \\
\hline${ }_{*}^{* *}$
\end{tabular}

e significativo a $1 \%$ e $5 \%$ de probabilidade pelo teste $\mathrm{F}$, respectivamente.

${ }^{\text {ns }}$ não significativo

De acordo com a equação apresentada na Figura 1, há forte evidência de que o aumento da tensão da água no solo em uma unidade implicará redução de $0,0852 \mathrm{~cm}$ na altura das plantas de alface para o intervalo estudado $(15,0 \mathrm{kPa}$ a $89,0 \mathrm{kPa})$. Isso quer dizer que, quanto mais próxima à tensão correspondente à capacidade de campo do solo estudado, mais altas são as plantas de alface. Assim, a umidade no solo parece favorecer de forma direta o desenvolvimento vegetativo dessa cultura.

A matéria fresca da parte comercial (MFPC) das plantas apresentou resposta linear inversa com o aumento da tensão de água no solo, a $1 \%$ de probabilidade (Figura 2). O máximo peso da matéria fresca da parte comercial foi atingido na tensão de $15 \mathrm{kPa}$, sendo esse valor igual a 661,72 g. Evidencia-se, portanto, a importância do fornecimento da água para a cultura, pois, nessa tensão, as irrigações foram distribuídas com maior freqüência ao longo do ciclo. A lâmina total de irrigação aplicada nesse tratamento foi $152,7 \mathrm{~mm}$. ANDRADE JÚNIOR (1994) obteve, com a aplicação de $142,3 \mathrm{~mm}$ na cultivar Mesa 659, o máximo peso total por planta de $802 \mathrm{~g}$, sob cultivo protegido. Esse valor máximo correspondeu a lâminas aplicadas a cada dois dias, referentes a $75 \%$ da evaporação do tanque Classe A. Para valores de lâminas acima de $75 \%$ da evaporação do tanque Classe A, houve redução no peso total por planta. 


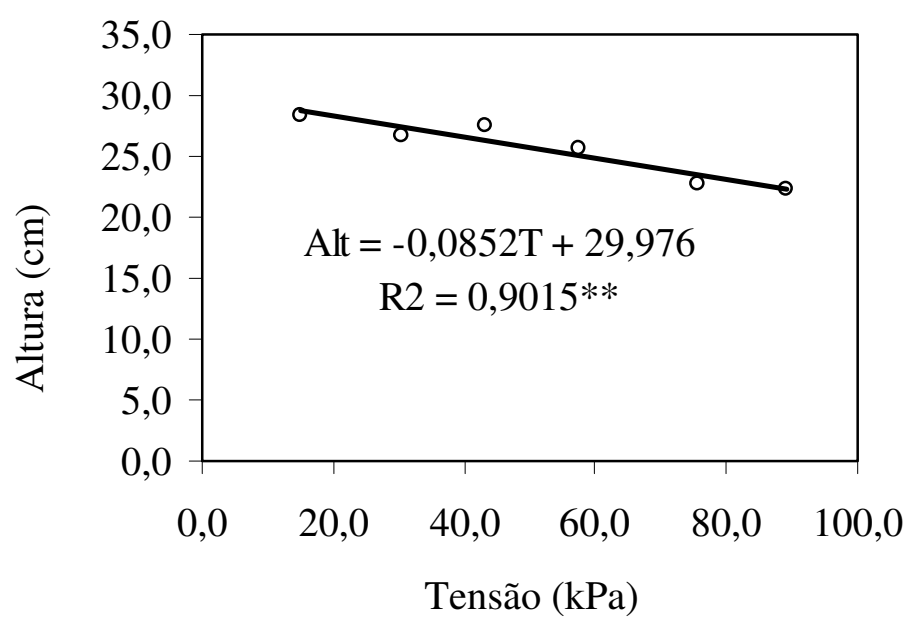

FIGURA 1. Altura de plantas sob influência de diferentes tensões de água no solo.

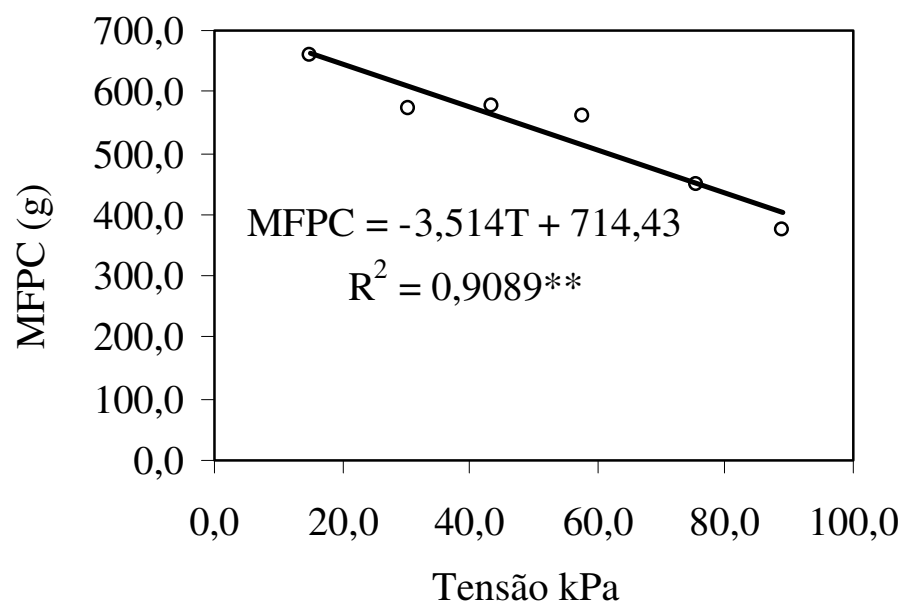

FIGURA 2. Matéria fresca da parte comercial (MFPC) de plantas sob influência de diferentes tensões da água no solo.

O peso máximo da MFPC de 661,72 g é um valor compatível com os obtidos em outros trabalhos. YURI (2000), em duas localidades do sul de Minas Gerais (Santo Antônio do Amparo e Boa Esperança), para a mesma cultivar aqui utilizada, obteve valores de $996 \mathrm{~g}$ e $711 \mathrm{~g}$, respectivamente. É importante comentar que, mesmo sendo numa época semelhante, as condições ambientais foram diferentes, bem como o tipo de experimento. O cultivo, neste caso, foi feito a campo. ALVARENGA (1999) obteve média de $577 \mathrm{~g}$, utilizando espaçamento similar e cultivando sob túneis altos.

$\mathrm{O}$ teor de matéria seca da parte comercial das plantas de alface aumentou linearmente com o aumento da tensão de água no solo (Figura 3). Como pode ser verificado na equação ali apresentada, o incremento na matéria seca comercial foi de $0,0173 \%$ por unidade acrescida de tensão de água no solo.

ANDRADE JÚNIOR (1994) obteve resultados semelhantes aos aqui apresentados para teor de matéria seca total, isto é, houve decréscimo no teor de matéria seca da parte aérea $(5,6$ a 4,7\%) com o aumento das lâminas aplicadas com base nas frações da evaporação no tanque Classe A $(0,25$ a 1,00). Segundo esse autor, as plantas, tendo maior disponibilidade de água, acumulam mais matéria fresca e reduzem a porcentagem de matéria seca, ou seja, aumentam o teor de água nos seus tecidos, "diluindo" a matéria seca. Realmente, ao se observar o comportamento da matéria fresca da parte comercial (Figura 2) e o do teor de matéria seca comercial, nota-se que mais matéria fresca foi obtida a tensões 
próximas à da capacidade de campo, por haver mais água disponível, decrescendo linearmente com o aumento da tensão. Com o teor de matéria seca da parte comercial, ocorreu o inverso: subiu de 2,60\%, à tensão de $15 \mathrm{kPa}$, para 3,89\%, à tensão de $89,0 \mathrm{kPa}$.

O teor da matéria seca fornece uma estimativa da quantidade de matéria sólida e de água incluída na produção. Se uma planta ou parte dela tiver menor teor de matéria seca, essa planta ou parte apresentará mais água em sua constituição, o que é desejável, porque a deixa mais tenra e com melhor sabor, apesar de a sua durabilidade pós-colheita ser menor (ALVARENGA, 1999). Sendo assim, o fato de a parte comercial das plantas ter menor teor de matéria seca nas tensões mais próximas à da capacidade de campo é vantajoso.

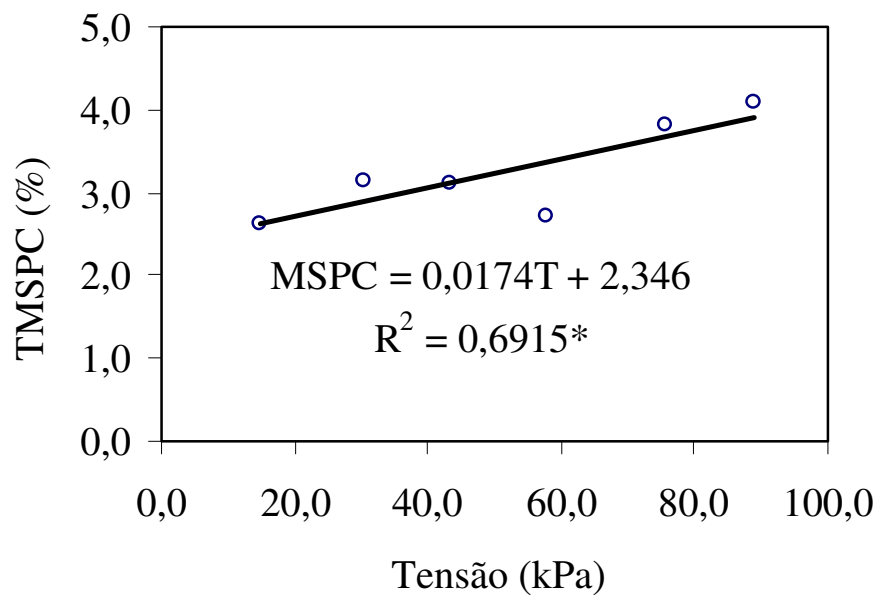

FIGURA 3. Teor de matéria seca da parte comercial (TMSPC) de plantas sob influência de diferentes tensões de água no solo.

A eficiência no uso da água (Ea) é a variável que mostra a relação produção da cultura/consumo de água.

Em relação à alface americana empregada no presente trabalho, a regressão quadrática pode ser usada para explicar as variações ocorridas com a Ea em função das diferentes tensões de água no solo (Tabela 2). A análise de variância não detectou diferença significativa entre os tratamentos para essa variável. O desdobramento da soma de quadrados de tratamentos na análise de variância, em diferentes efeitos de regressão, ao se tratar de níveis quantitativos, às vezes, pode detectar diferenças significativas (GOMES, 2000).

A mínima Ea $\left(380,62 \mathrm{~kg} \mathrm{ha}^{-1} \mathrm{~mm}^{-1}\right)$ foi obtida à tensão de 51,95 $\mathrm{kPa}$. Dentro da faixa estudada, os maiores valores de eficiência no uso da água $\left(469,2\right.$ e 469,7 $\mathrm{kg} \mathrm{ha}^{-1} \mathrm{~mm}^{-1}$ ) foram encontrados nas tensões de 15,0 kPa e 89,0 kPa, respectivamente (Figura 4). No sistema de irrigação por gotejamento, SAMMIS (1980) verificou, na tensão de $20 \mathrm{kPa}$, a eficiência no uso da água variando de $228 \mathrm{~kg} \mathrm{ha}^{-1} \mathrm{~mm}^{-1}$ a $771 \mathrm{~kg} \mathrm{ha}^{-1} \mathrm{~mm}^{-1}$, em três anos de cultivo da alface.

ANDRADE JÚNIOR (1994) obteve uma função linear decrescente entre níveis de água aplicados com base em tanque Classe A e Ea numa cultivar de alface americana, mostrando que os tratamentos com maior lâmina aplicada tenderam a apresentar menor Ea, os quais são resultados semelhantes aos aqui apresentados, considerando-se as lâminas aplicadas.

SANTOS (2002) também observou uma relação quadrática entre diferentes tensões empregadas na cultura do pepino e a Ea. $\mathrm{O}$ valor máximo da eficiência foi obtido quando o pepino foi submetido à tensão de $38,73 \mathrm{kPa}$ durante a fase reprodutiva. 


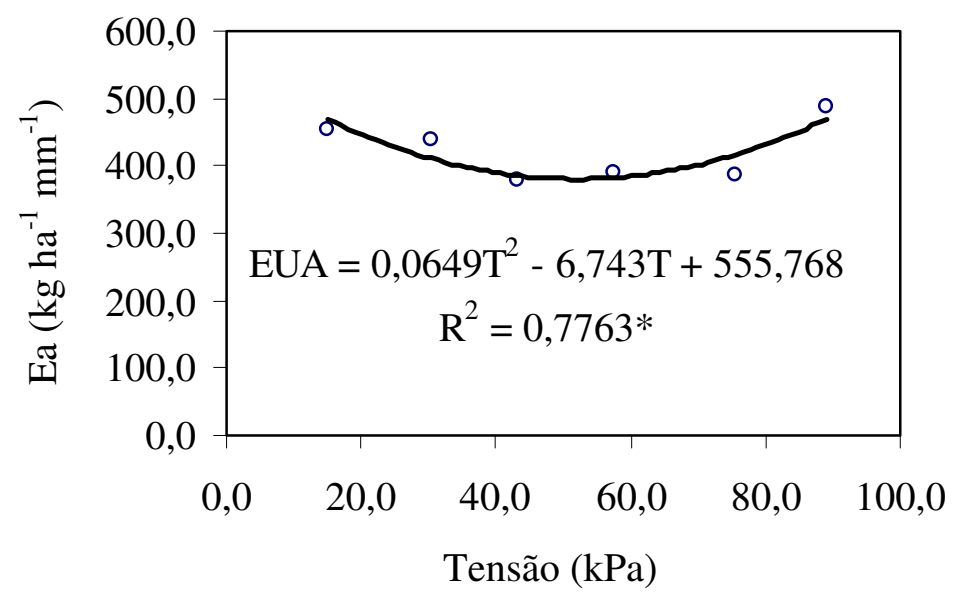

FIGURA 4. Eficiência no uso da água (Ea) de plantas sob influência de diferentes tensões de água no solo.

\section{CONCLUSÕES}

Para a obtenção de plantas mais altas, com maior peso de matéria fresca da parte comercial (cabeça comercial) e plantas com folhas mais tenras, as irrigações devem ser realizadas quando as tensões de água no solo estiverem em torno de $15 \mathrm{kPa}$, obtidas por sensores instalados a 0,15 m de profundidade.

A altura de plantas e o peso da matéria fresca da parte comercial reduziram-se linearmente em função do aumento da tensão da água no solo, no intervalo entre $15 \mathrm{kPa}$ e $89 \mathrm{kPa}$, ocorrendo o inverso com o teor de matéria seca.

A melhor eficiência no uso da água $\left(469,2 \mathrm{~kg} \mathrm{ha}^{-1} \mathrm{~mm}^{-1}\right)$ foi obtida com o controle da irrigação sendo realizado em torno de $15 \mathrm{kPa}$.

\section{AGRADECIMENTOS}

Ao Conselho Nacional de Desenvolvimento Científico e Tecnológico - CNPq, pelo auxílio financeiro concedido e ao Departamento de Engenharia da UFLA.

\section{REFERÊNCIAS}

ALVARENGA, M.A.R. Crescimento, teor e acúmulo de nutrientes em alface americana (Lactuca sativa L.) sob doses de nitrogênio aplicadas no solo e de níveis de cálcio aplicado via foliar. 1999. 117 f. Tese (Doutorado em Fitotecnia) - Universidade Federal de Lavras, Lavras, 1999.

ANDRADE JÚNIOR, A.S. de. Manejo da irrigação na cultura da alface (Lactuca sativa L.) através do tanque classe A. 1994. 104 f. Dissertação (Mestrado em Irrigação e Drenagem) - Faculdade de Ciências Agronômicas, Universidade Estadual Paulista, Botucatu, 1994.

EMPRESA BRASILEIRA DE PESQUISA AGROPECUÁRIA. Centro Nacional de Pesquisa de Solos. Sistema brasileiro de classificação de solos. Rio de Janeiro, 1999. 412 p.

FIGUERÊDO, S.F. Estabelecimento do momento de irrigação com base na tensão de água no solo para a cultura do feijoeiro. 1998. 94 f. Dissertação (Mestrado em Irrigação e Drenagem) - Escola Superior de Agricultura “Luiz de Queiroz”, Universidade de São Paulo, Piracicaba, 1998.

GENUCHTEN, M. van Th. A closed-form equation for predicting the hydraulic conductivity of unsaturated soils. Soil Science Society of American Journal, Madison, v.44, p.892-8, 1980. 
GOMES, F.P. Curso de estatística experimental. 14. ed. Piracicaba: ESALQ/USP, 2000. 477 p.

GOMES, L.A.A.; SILVA, E.C. da; FAQUIN, V. Recomendações de adubação para cultivos em ambiente protegido. In: RIBEIRO, A.C.; GUIMARÃES, P.T.G.; ALVAREZ, V.H. (Ed.).

Recomendações para o uso de corretivos e fertilizantes em Minas Gerais: $5^{\text {a }}$ aproximação. Viçosa MG: UFV, 1999. p.99-110.

INSTITUTO BRASILEIRO DE GEOGRAFIA E ESTATÍSTICA. Censo agropecuário. Rio de Janeiro, 1996. Disponível em: <http://www.sidra.ibge.gov.br/bda/horti/default.asp >. Acesso em: 14 set. 2002.

SAMMIS, T.W. Comparison of sprinkler, trickle, subsurface, and furrow irrigation methods for row crops. Agronomy Journal, Madison, v.72, n.5, p.701-4, 1980.

SANTOS, D.S. dos. Efeitos da tensão de água no solo, na cultura do pepino (Cucumis sativus L.), utilizando sistema de irrigação automatizado. 2002. 60 f. Dissertação (Mestrado em Irrigação e Drenagem) - Universidade Federal de Lavras, Lavras, 2002.

SEGOVIA, J.F.O.; ANDRIOLO, J.L.; BURIOL, G.A.; SCHNEIDER, F.M. Comparação do crescimento e desenvolvimento da alface (Lactuca sativa L.) no interior e exterior de uma estufa de polietileno em Santa Maria - RS. Ciência Rural, Santa Maria, v.27, n.1, p.37-41, 1997.

SILVA, W.L.C.; MAROUELLI, W.A. Manejo da irrigação em hortaliças no campo e em ambientes protegidos. In: FARIA, M.A.; SILVA, E.L.; VILELA, L.A.A.; SILVA, A.M. (Ed.). Manejo de irrigação. Poços de Caldas: UFLA/SBEA, 1998. p.311-48.

YURI, J.E. Avaliação de cultivares de alface americana em duas épocas de plantio em dois locais do Sul de Minas Gerais. 2000. 51 f. Dissertação (Mestrado em Fitotecnia) - Universidade Federal de Lavras, Lavras, 2000. 